\title{
Erratum to: The Genesis of Geometric Algebra: A Personal Retrospective
}

David Hestenes*

\section{Erratum to: Adv. Appl. Clifford Algebras (2017) 27:351-379 DOI 10.1007/s00006-016-0664-z}

Unfortunately, the reference Dechant [1] has been published with incorrect year, volume number and the page range. The correct reference is given below.

\section{Reference}

[1] Dechant, P.: Clifford algebra is the natural framework for root systems and Coxeter groups. Group theory: Coxeter, conformal and modular groups. Clifford Anal. Appl. 27, 17-31 (2017)

David Hestenes

Arizona State University

Tempe AZ 85287

USA

e-mail: hestenes@asu.edu

The online version of the original article can be found under doi:10.1007/s00006-016-0664-z.

${ }^{*}$ Corresponding author. 